\title{
Variations of Terrestrial Net Primary Productivity in East Asia
}

\author{
Fangmin Zhang ${ }^{1, *}$, Weimin $\mathrm{Ju}^{2}$, Shuanghe Shen ${ }^{1}$, Shaoqiang Wang ${ }^{3}$, Guirui $\mathrm{Yu}^{3}$, and Shijie Han ${ }^{4}$ \\ ${ }^{1}$ Jiangsu Key laboratory of Agricultural Meteorology, College of Applied Meteorology, \\ Nanjing University of Information Science and Technology, Nanjing, China \\ ${ }^{2}$ International Institute for Earth System Science, Nanjing University, Nanjing, China \\ ${ }^{3}$ Institute of Geographic Sciences and Natural Resources Research, \\ Chinese Academy Sciences, Beijing, China \\ ${ }^{4}$ State Key Laboratory of Forest and Soil Ecology, Institute of Applied Ecology, \\ Chinese Academy of Sciences, Shenyang, China
}

Received 24 October 2011, accepted 28 March 2012

\begin{abstract}
Due to the heterogeneity and complexity of terrestrial ecosystems of East Asia, a better understanding of relationships between climate change and net primary productivity (NPP) distribution is important to predict future carbon dynamics. The objective of this study is to analyze the temporal-spatial patterns of NPP in East Asia $\left(10^{\circ} \mathrm{S}-55^{\circ} \mathrm{N}, 60-155^{\circ} \mathrm{E}\right)$ from 1982 to 2006 using the process-based Boreal Ecosystem Productivity Simulator (BEPS) model. Prior to the regional simulation, the annual simulated NPP was validated using field observed NPP demonstrating the ability of BEPS to simulate NPP in different ecosystems of East Asia.

Simulated NPP exhibited a southeast-northwest decreasing distribution, above $1000 \mathrm{~g} \mathrm{C} \mathrm{m}^{-2} \mathrm{yr}^{-1}$ in most areas of Southeast Asia and below $50 \mathrm{~g} \mathrm{C} \mathrm{m}^{-2} \mathrm{yr}^{-1}$ in northwestern China. The annual total of simulated NPP was $11.27 \mathrm{Pg} \mathrm{C} \mathrm{yr}^{-1}(\sim 18.78 \%$ of the global total) averaged over 25 years from 1982 to 2006 . Total NPP increased by $7.33 \%$, mainly in the northwestern part of the study area. The change of NPP was determined by precipitation in northern and southwestern regions, vapor pressure deficit and precipitation in North and Northeast Plains of China, radiation in South China, and temperature on the Tibetan Plateau. Climate was the main factor regulating the NPP trends in the interior and northern parts of the study area while the change in leaf area index was the factor dominating the trends of NPP in the eastern part of the study area.
\end{abstract}

Key words: Net primary productivity, BEPS model, East Asia, Remote sensing, Climate change, Vegetation change

Citation: Zhang, F., W. Ju, S. Shen, S. Wang, G. Yu, and S. Han, 2012: Variations of terrestrial net primary productivity in East Asia. Terr. Atmos. Ocean. Sci., 23, 425-437, doi: 10.3319/TAO.2012.03.28.01(A)

\section{INTRODUCTION}

As an important component of the terrestrial carbon cycle, net primary productivity (NPP) is a measure of the uptake of atmospheric $\mathrm{CO}_{2}$ by plant photosynthesis. Without consideration of ecosystem disturbances, the balance between NPP and heterotrophic respiration $\left(\mathrm{R}_{\mathrm{h}}\right)$ released from soils determines whether an ecosystem is a carbon sink or source (Piao et al. 2009). NPP is an indicator of climate change (Nemani et al. 2003). Therefore, a better understanding in spatio-temporal variations in NPP and its feedback on climate change will improve the prediction of future terrestrial carbon flux (Houghton et al. 2001).

\footnotetext{
* Corresponding author

E-mail:fmin.zhang@utoronto.ca
}

In East Asia, significant human-induced changes in land cover types, considerable application of artificial fertilizers, and large temporal and spatial variations of climate make it more challenging to calculate NPP reliably in this region than in other regions (Ito 2008). Remote sensing is able to detect the response of vegetation to the integrated effects of multiple environmental factors and human activities and provide an opportunity to improve the estimation of NPP.

The El Niño/Southern Oscillation (ENSO) is a global phenomenon of surface temperature abnormality in near tropical seas and significantly affects atmospheric circulation and precipitation patterns (Ropelewski and Halpert 1987). The ENSO has two different phases, namely a 
warming El Niño phase and a cooling La Niña phase. The ENSO often causes floods, droughts and other extreme climatic disasters, which also have significant effects on NPP of terrestrial ecosystems (Nemani et al. 2003; Hashimoto et al. 2004).

In recent years, a few efforts have been made to investigate the productivity of terrestrial ecosystems in East Asia using satellite datasets and models. Matsushita and Tamura (2002) simulated a total NPP in 1998 over East Asia covering $9^{\circ} \mathrm{S}-66^{\circ} \mathrm{N}$ and $78-170^{\circ} \mathrm{E}$ amounted to $25.7 \mathrm{Pg} \mathrm{C} \mathrm{yr}^{-1}$ using the Boreal Ecosystem Productivity Simulator (BEPS) model. Li et al. (2008) reported that the total NPP in 1999 in East Asia $\left(10-70^{\circ} \mathrm{N}, 70-170^{\circ} \mathrm{E}\right)$ was $14.43 \mathrm{Pg} \mathrm{C} \mathrm{yr}^{-1}$ while Yu et al. (2009) concluded that the total NPP in 1999 for the same area was $10.96 \mathrm{Pg} \mathrm{C} \mathrm{yr}^{-1}$ even though they both used the Carnegie Ames Stanford Approach (CASA) biosphere model and similar input datasets. Existing results on the temporal and spatial patterns of NPP and its responses to climate change in East Asia are not consistent. Based on the simulation using the Production Efficiency Model, Nemani et al. (2003) pointed out that the limiting factor of NPP in East Asia varied spatially during the period from 1982 to 1999. Water acted as the key determinant of NPP in arid and semiarid areas, such as northwestern China and Mongolia. NPP was mainly limited by temperature in eastern Siberia and by radiation in Southeast Asia. However, Piao et al. (2009) pointed out that precipitation was the major driver of NPP in East Asia with the exception of Tibetan Plateau. In a synthesis study using three different dynamic vegetation models, NPP exhibited different trends in Mongolia and Northeast China (Piao et al. 2009). Such existing uncertainties and inconsistencies in the current NPP estimates are mainly due to the heterogeneity and complexity of terrestrial ecosystems in East Asia and our limited knowledge on the mechanisms affecting NPP (Ito 2008).

In this study, the spatial and temporal variations of NPP and its response to climate change in East Asia from 1982 to 2006 are analyzed using a process-based BEPS model driven via meteorological data and remotely sensed vegetation parameters. Prior to the regional simulation, the BEPS model was validated using field measured NPP. The objectives of this study are: (1) to quantify the spatio-temporal patterns of NPP in East Asia from 1982 to 2006, and (2) identify the roles of vegetation and climatic factors in determining the temporal trends of NPP in different areas of East Asia. By integrating process-based ecological model with remote sensing data, our approach might provide a more reliable estimate of regional NPP and a new perspective to understand the underlying drivers of NPP changes in East Asia. This study also provides a reference for verifying previous studies with regard to the terrestrial carbon cycle in this region. It would be valuable for reducing the current uncertainties in terrestrial carbon budget estimated using bottom-up modeling strategies.

\section{MATERIALS AND METHODS}

\subsection{Study Area}

The study area of East Asia $\left(10^{\circ} \mathrm{S}-55^{\circ} \mathrm{N}, 60-155^{\circ} \mathrm{E}\right)$ extends from the subarctic to tropical regions (Fig. 1). The northwestern and southeastern parts of this area are dominated by forests. Grassland is the major land cover in the northwest. Cropland occupies most land areas in eastern China, South Asia and the northern part of Southeast Asia. Climatic conditions vary widely. The Asian monsoon causes sizable interannual and seasonal variations in meteorological variables, which in turn affect terrestrial ecosystems. Intensive human activities here result in considerable changes in land use and land cover.

\subsection{The Model Used}

Originating from the FOREST-BGC model (Running and Coughlan 1988), the BEPS model used in this study was designed initially to simulate NPP for Canada's landmass at daily time steps (Liu et al. 1997). The model has been updated and used widely in other countries and regions including East Asia (Zhang et al. 2010), North America (Sprintsin et al. 2012), as well as globally (Chen et al. 2012). More details about the BEPS model have been introduced in previous studies (such as Liu et al. 1997, 2002; Chen et al. 1999, 2012; Ju et al. 2010). The instantaneous photosynthetic rates of two leaf groups (sunlit and shaded) are calculated using Farquhar's leaf-level biochemical model and up-scaled to daily values using a temporal scaling scheme (Chen et al. 1999). The gross primary productivity (GPP) of canopy is the sum of GPP of sunlit and shaded leaves. The NPP is calculated as the difference between daily GPP and autotrophic respiration, which consists of growth respiration and maintenance respiration. The former is set as $25 \%$ of GPP while the latter is estimated according to the respiration rate at the base temperature and the sensitivity of respiration to temperature $\left(\mathrm{Q}_{10}\right)$ of four different biomass pools (foliage, stem, coarse roots, and fine roots), respectively. To initialize our simulations, we conduct a one-year spin-up (the year of 1982) to equilibrate the model dynamically. Prior to the regional simulation in East Asia, the model has been parameterized based on 20 AsiaFlux sites (Zhang et al. 2010). The values of key parameters used in this study are listed in Table 1.

\subsection{Input Data}

\subsubsection{Land Cover Data}

Land cover is a key input into the model because parameters such as maximum stomatal conductance $\left(\mathrm{g}_{\max }\right)$, maximum carboxylation $\left(\mathrm{V}_{\mathrm{cmax}}\right)$, respiration rates, and foliage clumping index are land-cover-related. The land cover map at $8-\mathrm{km}$ resolution used here (Fig. 1) was subtracted 
(a)

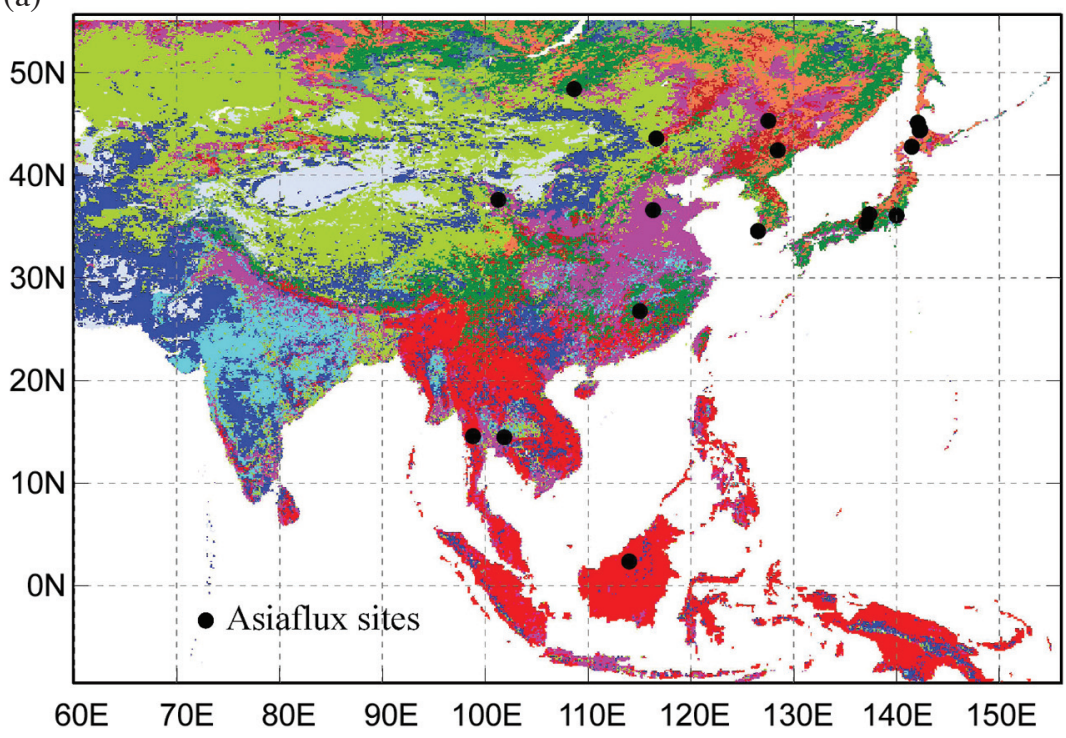

(b)

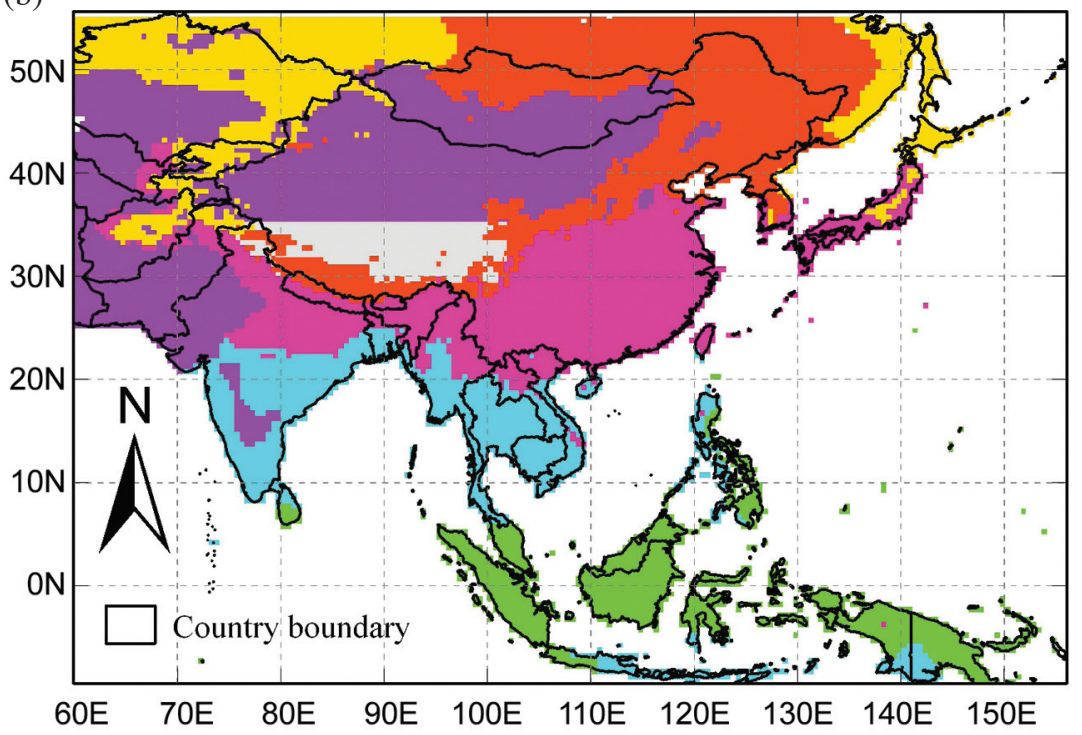

Evergreen needle-leaf forest (ENF)

$\square$ Deciduous needle-leaf forest (DNF)

Deciduous broadleaf forest (DBF)

Mixed forest (MF)

Cropland

Bare land

Evergreen broadleaf forest (EBF)

Wooded grassland

Shrubland

Grassland

Urban and Built-up
Dw: east continental climate

Df: west continental climate

Af: equatorial climate

Am_Aw: tropical savanna and monsoon climate

Cf_Cw: subtropical climate

Bs_Bw: desert and semi-arid climate

ET: tundra climate

Fig. 1. The land cover map from GLCF and climate zones based on Koppen-Geiger climate classifications overlaying the boundaries of countries in East Asia.

Table 1. The parameters used in this study.

\begin{tabular}{|c|c|c|c|c|c|c|c|c|c|c|c|}
\hline Parameters & Units & ENF & EBF & DNF & DBF & MF & Shrub & Grass & Crop & Others & References \\
\hline Specific leaf area & $\mathrm{m}^{2} \mathrm{~kg}^{-1} \mathrm{C}$ & 20 & 17.5 & 30 & 26.2 & 20 & 15 & 25 & 30 & 15 & This study \\
\hline Max. canopy conductance & $\mathrm{H}_{2} \mathrm{O} \mathrm{m} \mathrm{s}^{-1}$ & 0.0036 & 0.006 & 0.002 & 0.005 & 0.004 & 0.004 & 0.005 & 0.006 & 0.0016 & This study \\
\hline Leaf respiration coefficient & $\mathrm{kg} \mathrm{C}$ day $^{-1} \mathrm{~kg}^{-1}$ & 0.0022 & 0.0035 & 0.002 & 0.004 & 0.0042 & 0.006 & 0.0007 & 0.0008 & 0.0008 & This study \\
\hline Stem respiration coefficient & $\mathrm{kg} \mathrm{C}$ day $^{-1} \mathrm{~kg}^{-1}$ & 0.001 & 0.001 & 0.001 & 0.001 & 0.001 & 0.001 & 0.001 & 0.001 & 0.001 & $\begin{array}{l}\text { Running and } \\
\text { Coughlan (1988) }\end{array}$ \\
\hline Fine root respiration coefficient & $\mathrm{kg} \mathrm{C}$ day $^{-1} \mathrm{~kg}^{-1}$ & 0.003 & 0.003 & 0.003 & 0.003 & 0.003 & 0.003 & 0.003 & 0.003 & 0.003 & This study \\
\hline Coarse root respiration coefficient & $\mathrm{kg} \mathrm{C}$ day $^{-1} \mathrm{~kg}^{-1}$ & 0.001 & 0.001 & 0.001 & 0.001 & 0.001 & 0.001 & 0.0015 & 0.0015 & 0.0015 & Foley (1996) \\
\hline Snowmelt Temp Coefficient & $\mathrm{m} \mathrm{day}^{-1}{ }^{\circ} \mathrm{C}^{-1}$ & 0.0022 & 0.001 & 0.0022 & 0.001 & 0.0015 & 0.002 & 0.001 & 0.001 & 0.0006 & Kite (1988) \\
\hline Clumping index & & 0.6 & 0.8 & 0.6 & 0.8 & 0.7 & 0.5 & 0.9 & 0.9 & 1 & Liu et al. (2007) \\
\hline
\end{tabular}


from the global GLCF land cover dataset (Hansen et al. 1998) due to the reliability and wide applications of this dataset (Ito 2008). In this dataset, there are totally 13 land cover types, including evergreen needle-leaf forest, evergreen broadleaf forest, deciduous needle-leaf forest, deciduous broadleaf forest, mixed forest, woodland, wooded grassland, closed shrub land, open shrub land, grassland, cropland, bare ground, and urban and built-up land.

\subsubsection{Leaf Area Index Data}

The leaf area index (LAI) is another key input into the BEPS model. It determines radiation transfer, the ratio of sunlit leaves to shaded leaves, precipitation interception, photosynthesis rate, and autotrophic respiration rate. The time series of LAI at 8-km resolution from 1982 to 2006 was created from the NOAA/AVHRR 15-day composite images of Normalized Difference Vegetation Index (NDVI) downloaded from Global Inventory Modeling and Mapping Studies (GIMMS) data set (Zhou et al. 2001). Similar to Nemani et al. (2003), the conversion of NDVI to LAI here was based on the NDVI-LAI look up table constructed by Myneni et al. (2002). The converted LAI was further smoothed with the Locally Adjusted Cubic-spline Capping (LACC) method developed by Chen et al. (2006) to constrain the impacts of residual cloudy contamination on the seasonal trajectories of LAI. The LACC method eliminates the problem of rigid seasonal trajectory shapes caused by simple overlapping of a few harmonics in the existing methods of Fourier-Adjustment, Solar zenith angle correction, Interpolation and Reconstruction (FASIR) and Atmospheric, Bidirectional, and Contamination corrections (ABC3) (Pisek and Chen 2007). The resulting 15-day LAI was linearly interpolated to produce daily LAI, which was required to drive the model.

\subsubsection{Meteorological Data}

The daily reanalysis meteorological data with Gauss grid $\left(\sim 1.875^{\circ}\right)$ from 1982 to 2006 were downloaded from the US National Centers for Environmental Prediction (NCEP). The dataset includes the daily maximum and minimum temperatures, pressure, specific humidity, incoming solar radiation, precipitation and wind velocity. They were spatially interpolated using the bilinear interpolation method to produce regional meteorological fields as inputs into the model.

In order to consider the effects of local topography on the spatial variations of temperature and precipitation, the coarse resolution (about $200 \mathrm{~km}$ ) NCEP reanalysis temperature and precipitation data were superimposed on re-sampled 8-km Worldclim data (Hijmans et al. 2005) to produce 8-km datasets of daily maximum and minimum temperatures and precipitation (Ito 2008):

$$
\left\{\begin{array}{r}
T(i, j, d)=T_{n c}(i, j, d)+\bar{T}_{w c}(i, j, m)-\bar{T}_{n c}(i, j, m) \\
\text { for temperature } \\
R(i, j, d)=R_{n c}(i, j, d) \bar{R}_{w c}(i, j, m) / \bar{R}_{n c}(i, j, m) \\
\text { for precipitation }
\end{array}\right.
$$

where $i$ and $j$ denote the row and column numbers, respectively; $T(i, j, d)$ is the resulting 8 -km daily maximum/minimum temperature in day $d ; T_{n c}(i, j, d)$ is the daily maximum/ minimum temperature interpolated from the NCEP data in day $d ; \bar{T}_{w c}(i, j, m)$ is the monthly mean of maximum/ minimum temperature from the WorldClim data in month $m ; \bar{T}_{n c}(i, j, m)$ is the monthly mean of maximum/minimum temperature from the NCEP data in month $m ; R(i, j, d)$ is the resulting 8-km daily precipitation in day $d ; R_{n c}(i, j, d)$ is daily precipitation interpolated from the NCEP data in day $d ; \bar{R}_{w c}(i, j, m)$ is the monthly total precipitation from the WorldClim data in month $m ; \bar{R}_{n c}(i, j, m)$ is the monthly total precipitation from the NCEP data in month $m$.

The systematic overestimation of the NCEP radiation data was corrected following Feng et al. (2007). The average relative humidity $(\mathrm{RH})$ and vapor pressure deficit (VPD) were calculated according to temperature, specific humidity, and air pressure.

The atmospheric $\mathrm{CO}_{2}$ concentrations used are the annual means measured at Mauna Loa Observatory (MLO) in Hawaii $\left(20^{\circ} \mathrm{N}, 156^{\circ} \mathrm{W}\right)$ (Keeling et al. 2009; http://cdiac. esd.ornl.gov/ftp/trends/CO2/maunaloa.CO2). We assumed $\mathrm{CO}_{2}$ concentrations were constant across the study area.

ENSO is an important coupled ocean-atmosphere phenomenon to cause global climate abnormality. The Multivariate ENSO index (MEI) was used as an indicator of ENSO (Wolter and Timlin 1998; http://www.cdc.noaa.gov/ people/klaus.wolter/MEI/mei.html) to study the behavior of NPP in the study area in ENSO years.

\subsubsection{Soil Data}

Available water-holding capacity (AWC) in the root zone is the difference between field capacity and wilting point, representing the maximum amount of water available for the uptake by plants. In this study, the $0.5^{\circ}$ soil data from the International Geosphere-Biosphere Program, Data and Information System (IGBP-DIS, 2000; http://www.daac. ornl.gov) were bilinearly interpolated and then processed to produce the AWC data.

\subsubsection{Measured NPP Data}

NPP compiled from the GPPDI dataset (Zheng et al. 2003; http://www-eosdis.ornl.gov) and the database created by Luo (1996) was used to validate NPP simulated by BEPS. The GPPDI database was generated from various sources 
for the purpose to parameterize, calibrate and validate models to estimate global NPP (Hazarika et al. 2005), while the NPP database of Luo (1996) was constructed based on forest inventory data from China. Within an $8 \mathrm{~km} \times 8 \mathrm{~km}$ grid of the BEPS model domain, there are possibly several NPP values from the GDDDI or Luo NPP database within one pixel. These NPP values in a grid cell were averaged for validating simulated NPP. Totally, there are 1300 measured NPP values from the GDDDI and Luo NPP databases in different regions.

\subsection{Modeling Experiments}

Four simulations were conducted in this study (Table 2). In Simulation I, historical climate and LAI from 1982 to 2006 were used to investigate the spatial and temporal trends of NPP in East Asia. In Simulation II, NPP was simulated using historical climate and daily average LAI from 1982 to 2006. In Simulation III, the model was forced by historical LAI and daily average climate from 1982 to 2006. In Simulation IV, the model was forced by both daily climate and the LAI averaged from 1982 to 2006. These simulations were used to assess the effects of climate and vegetation (indicated by LAI) changes on NPP.

\section{RESULTS}

\subsection{Modeling Validation}

Figure 2 presents the comparison of simulated annual NPP against the corresponding NPP values compiled from the GPPDI and Luo databases. The model explained $78 \%$ of NPP variations among 1300 sampling sites $\left(R^{2}=0.78\right.$, RMSE $\left.=118 \mathrm{~g} \mathrm{C} \mathrm{yr}^{-1}, \mathrm{p}<0.01\right)$. Simulated NPP on average was $7.9 \%$ lower than measured NPP in these sites, mainly caused by the underestimation of simulated NPP in sites with measured NPP above $1200 \mathrm{~g} \mathrm{C} \mathrm{m}^{-2} \mathrm{yr}^{-1}$. The differences between measured and modeled values are related possibly to the scale mismatch and the uncertainties of input data such as the saturation in LAI. The NPP was measured at plots normally smaller than one hectare while the simulated NPP is the aggregation of values within an $8 \mathrm{~km}$ $\times 8 \mathrm{~km}$ grid cell. The LAI used here was converted from NDVI, which might be saturated under the condition of high vegetation density. Generally, simulated and measured NPP agree well. The validation demonstrates the acceptability of the BEPS model to simulate NPP in the study area.

\subsection{Spatial Distribution of Simulated NPP}

Simulated NPP averaged during the period of 1982 - 2006 exhibited a distinct spatial pattern in East Asia decreasing from monsoon climate zones in the south to interior mainland areas (Fig. 3a). The NPP was the highest in tropical broadleaf forests in Southeast Asian island coun- tries. Annual NPP on average was in the range from 1000 to $2000 \mathrm{~g} \mathrm{C} \mathrm{m}^{-2} \mathrm{yr}^{-1}$ in this area. Simulated NPP of evergreen broadleaf forests in Cambodia, Laos and Vietnam ranged from 800 to $1500 \mathrm{~g} \mathrm{C} \mathrm{m}^{-2} \mathrm{yr}^{-1}$. The NPP in Japan, South Korea, North Korea, Northeast China, and eastern Russia was in the range from 700 to $1100 \mathrm{~g} \mathrm{C} \mathrm{m}^{-2} \mathrm{yr}^{-1}$. The NPP in the India Peninsula was relatively low, ranging from 200 to $400 \mathrm{~g} \mathrm{C} \mathrm{m}^{-2} \mathrm{yr}^{-1}$. In the arid areas of the middle and western parts of the study area, NPP was normally less than $50 \mathrm{~g} \mathrm{C} \mathrm{m}^{-2} \mathrm{yr}^{-1}$ due to seriously limited photosynthesis by low water availability.

The changes in NPP were spatially homogenous (Fig. 3b) during the period from 1982 to 2006 . The significant increase of NPP occurred in the India Peninsula, Kyrgyzstan, Kazakhstan, and some areas in South and Southeast Asia with increasing rates from 6 to $10 \mathrm{~g} \mathrm{C} \mathrm{m}^{-2} \mathrm{yr}^{-2}(\mathrm{p}<$ $0.01)$. In contrast, the significant decrease of NPP occurred in partial areas of Northeast Asia, South China, Laos, Cambodia and Vietnam with decreasing rates above $6 \mathrm{~g} \mathrm{C} \mathrm{m}^{-2} \mathrm{yr}^{-2}$ $(\mathrm{p}<0.01)$.

\subsection{Temporal Trends of Total NPP}

The annual total NPP averaged over the period of 1982

Table 2. Designs for four simulations.

\begin{tabular}{cccc}
\hline NO. & Scenario & Climate & LAI \\
\hline I & All effects & Historical & Historical \\
II & Climate effect & Historical & Average \\
III & Vegetation effect & Average & Historical \\
IV & Baseline & Average & Average \\
\hline
\end{tabular}

Note: "Climate" indicates the combination of precipitation, temperature, vapor pressure deficit and radiation in this study. "Average" means data were held at the averaged level of $1982-2006$ and was unchanged during the simulation period from 1982 to 2006 . "Historical" means long-term daily historical changes during the simulation period of 1982 - 2006.

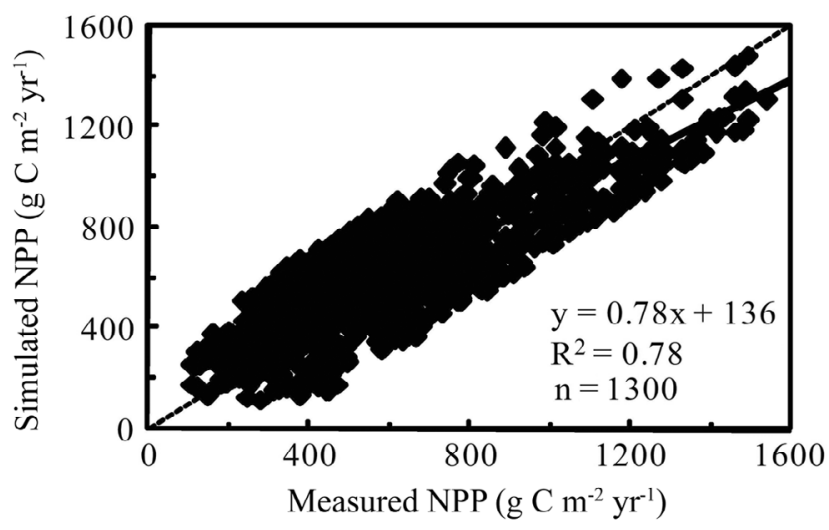

Fig. 2. Comparison of simulated annual net primary productivity (NPP) with the corresponding compiled from databases of GPPDI and Luo. 
(a)

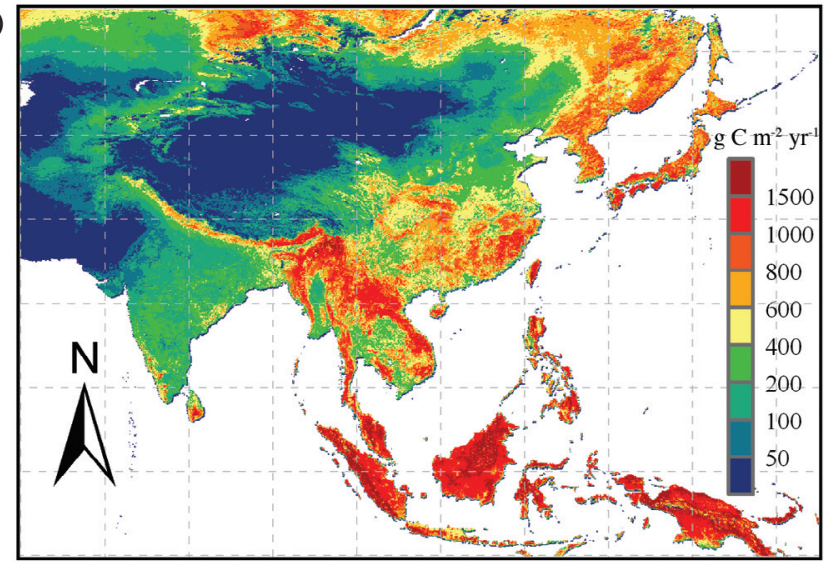

(c)

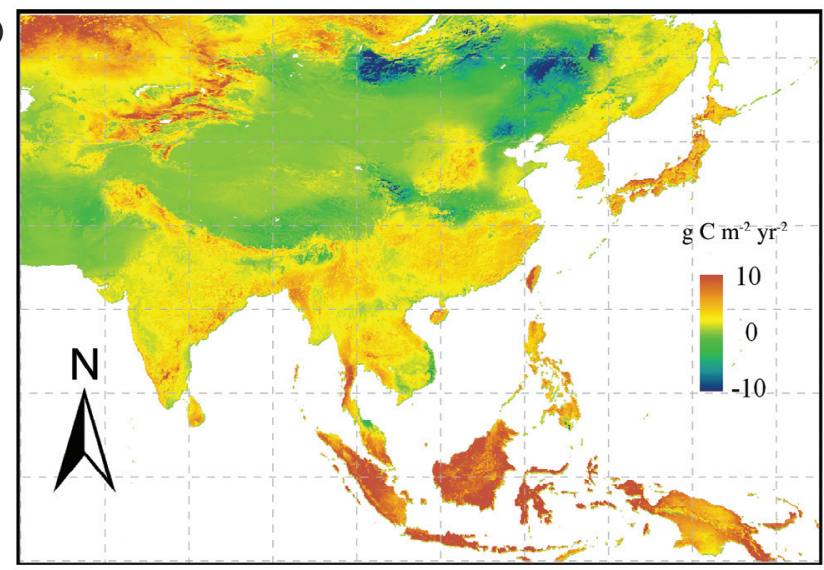

(b)

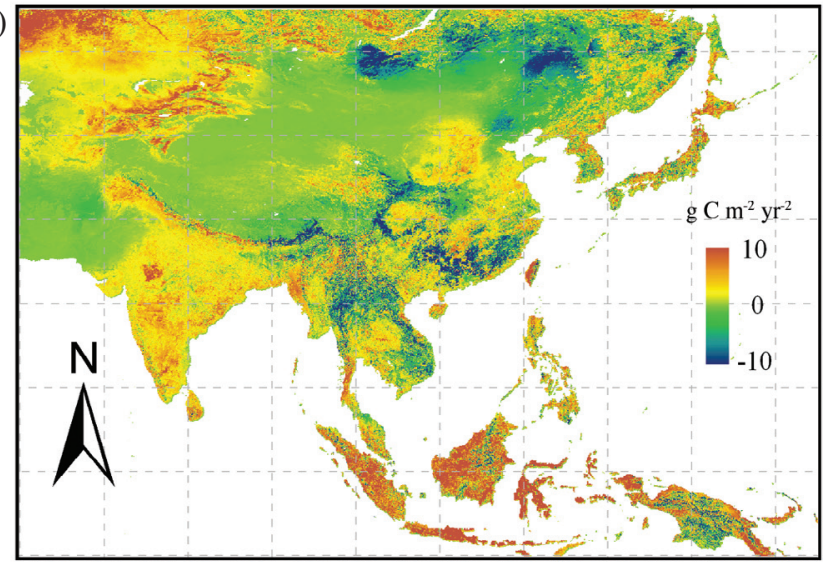

(d)

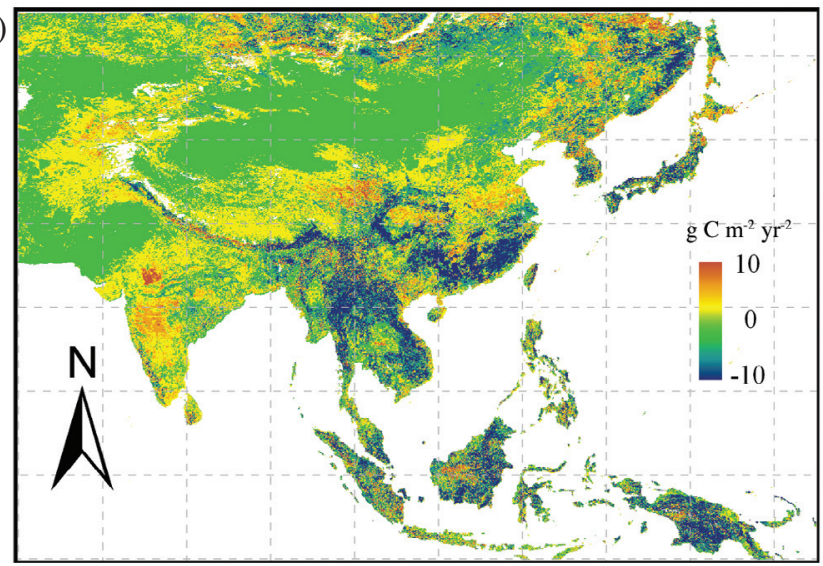

Fig. 3. Spatial distribution of (a) average annual net primary productivity (NPP) in simulation I and (b) - (d) temporal change rates of NPP in Simulation I, Simulation II, and Simulation III from 1982 to 2006, respectively. Simulation I: both climate and LAI changed with time. Simulation II: climate changed with time while leaf area index (LAI) was retained as the averages over the study period. Simulation III: LAI changed with time while climate was retained as the averages over the study period.

- 2006 was $11.27 \mathrm{Pg} \mathrm{C} \mathrm{yr}^{-1}$ (Fig. 4a), approximately equivalent to $18.78 \%$ of the global total. $71 \%$ of total NPP was produced in the east continental (Dw), subtropical (Cf_Cw) and tropical (Af) climate zones (Figs. 4b - g) based on Koppen-Geiger climate classifications (Fig. 1).

Simulated annual total NPP in East Asia increased significantly by $7.33 \%(\mathrm{p}<0.001)$ from $10.83 \mathrm{Pg} \mathrm{C} \mathrm{yr}^{-1}$ averaged in years from 1982 to 1985 to an average of 11.62 $\mathrm{Pg} \mathrm{C} \mathrm{yr}^{-1}$ in years of 2005 and 2006 (Fig. 4a). This number is slightly larger than the increase rate of $6.0 \%$ in global annual NPP during the period from 1982 to 1999 reported by Nemani et al. (2003). The ecosystems in the Af and tropical savanna and monsoon climate (Am_Aw) zones contributed to $90 \%$ of the NPP increase whereas NPP of ecosystems in the Dw zone decreased by about $15 \%$ (Figs. 4b-g).

\subsection{Effects of Changing Climate and Vegetation on NPP}

During the study period, annual total NPP on average was $11.03 \mathrm{Pg} \mathrm{C} \mathrm{yr}^{-1}$ if only considering climate change,
2.17\% lower than the corresponding value when climate and vegetation changed simultaneously. Changes in climate resulted in NPP to increase in $60 \%$ of the study areas such as in Kazakhstan, Japan, South China, India and Southeast Asia, with average increase rates of around $5 \mathrm{~g} \mathrm{C} \mathrm{m}^{-2} \mathrm{yr}^{-2}$ $(\mathrm{p}<0.01)$. The decrease in NPP caused by only climate change occurred mainly in Mongolia, Northeast China and North Plain of China, with average decreasing rates of around $7 \mathrm{~g} \mathrm{C} \mathrm{m}^{-2} \mathrm{yr}^{-2}$ ( $\mathrm{p}<0.01$ ) (Fig. 3c). In contrast, annual

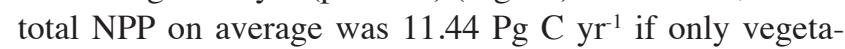
tion change occurred during the study period, $1.54 \%$ higher than the corresponding value when both climate and vegetation changed. The changes in vegetation caused NPP to decrease at average rates of around $8 \mathrm{~g} \mathrm{C} \mathrm{m}^{-2} \mathrm{yr}^{-2}$ in areas of Russia, Japan, South China and Southeast Asia ( $<<0.01)$ and to increase at average rates of around $4 \mathrm{~g} \mathrm{C} \mathrm{m}^{-2} \mathrm{yr}^{-2}$ in India, North Plain of China and Southeast Asia $(\mathrm{p}<0.01)$ (Fig. 3d).

In areas in which declining vegetation (decreasing LAI) alone caused NPP to decrease significantly, NPP simulated under the condition that climate and vegetation changed 


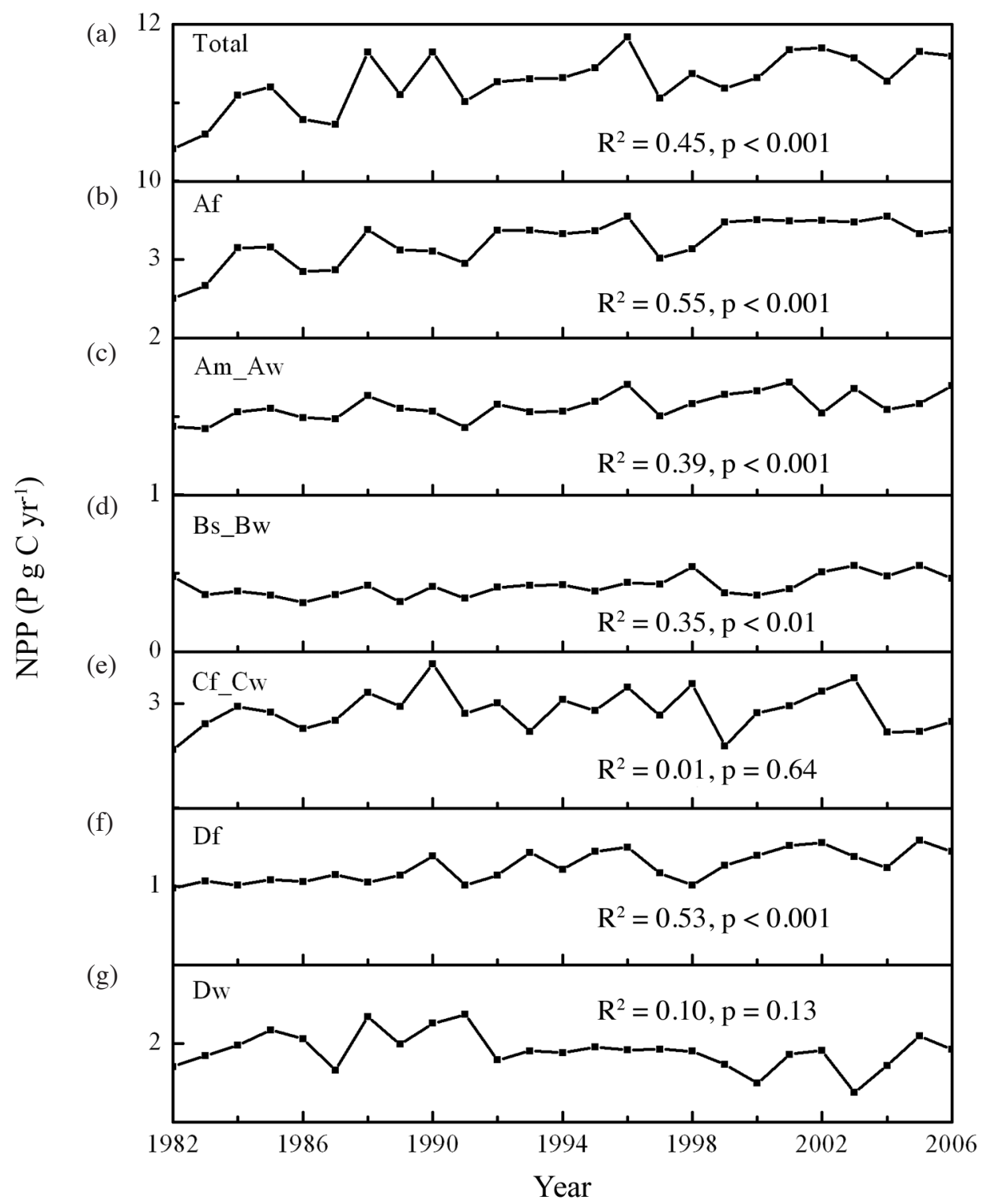

Fig. 4. Temporal trends of simulated annual total net primary productivity (NPP) in (a) the entire study region and (b) - (g) seven climate zones based on the Koppen-Geiger climate classifications. The meaning of climate zone symbols of such as "Af," "Am_Aw" is in Fig. 1. The coefficient of determination $\left(\mathrm{R}^{2}\right)$ is between year and NPP. The $\mathrm{p}$ value represents the significant level.

simultaneously exhibited decreasing trends even if climate change had positive effects on simulated NPP. In contrast, in areas, such as the western study area, Mongolia and Northeast China, in which vegetation change alone did not cause NPP to change significantly, NPP simulated with both of climate and vegetation changes exhibited similar temporal trends to NPP simulated with climate change alone. It indicates that climate change was the major determinant of NPP trends under the condition that vegetation did not change significantly during our study period. Otherwise, vegetation change was the dominant factor determining the temporal trends of NPP.

In general, climate change predominantly regulated the decreasing trends of NPP in Mongolia, North and Northeast
Plain in China and increasing trends in Kazakhstan. Vegetation change played a dominant role in inducing the decreasing trends of NPP in pan Southeast Asia, South China, Japan and areas in Russia. Climate and vegetation changes induced significant increases in NPP in India.

\section{DISCUSSION}

\subsection{Responses of NPP to NDVI}

NDVI acting as the source of LAI in this study was one of the major factors driving the increase in total NPP. The dependence of NPP on NDVI in China during the period from 1982 to 1999 identified in this study was weaker than the finding of Piao et al. (2005), who reported a strong 
correlation between NPP and NDVI using the CASA model. The different degrees of correlation between NDVI and NPP in our study and Piao et al. (2005) may be primarily due to the difference in the models used. In the CASA model used by Piao et al. (2005), the NPP was calculated as a product of light use efficiency, absorbed photosynthetically active radiation (APAR), which equals to incoming solar radiation multiplied by the fraction of photosynthetically active radiation absorbed by vegetation (FPAR). FPAR is positively related to NDVI. In the process-based BEPS model, NPP equals to the residual of GPP minus autotrophic respiration. The GPP is calculated by scaling up Farquhar's instantaneous leaf biochemical model to the canopy level. GPP is nonlinearly positively related to LAI, temperature, incoming solar radiation, soil water content and is negatively related to VPD (Chen et al. 1999). Autotrophic respiration is estimated according to the LAI, temperature and base respiration rates of different biomass pools. The increase in NDVI results in both increases in GPP and autotrophic respiration. Thus, NPP simulated by BEPS was less sensitive to NDVI than NPP simulated by the CASA model and implies that the positive effect of NDVI on NPP might be overestimated by the CASA model since it assumes a significant increase of APAR with NDVI and ignores the increase of respiration associated with increasing NDVI.

\subsection{Effects of Changing Climate on NPP}

We analyzed the trends of climate factors (such as temperature, precipitation, VPD and radiation) affecting NPP during the period from 1982 to 2006. Temperature increased in most eastern and northern areas whereas it decreased in India Peninsula, southeastern Tibetan Plateau and some areas in Indonesia (Fig. 5a). VPD increased in eastern part of the study region with the exception of Japan and decreased in pan Southeast Asia, India Peninsula, western China and Mongolia (Fig. 5b). Radiation decreased significantly in northwestern China and Kazakhstan and increased significantly in Pakistan, India and eastern China (Fig. 5c). Precipitation increased significantly in India, Indo-China Peninsula, Kazakhstan and Japan and decreased significantly in southwestern Tibetan Plateau, Mongolia, Northeast China and Pakistan (Fig. 5d).

The NPP changes were influenced by different climate factors in different areas. Increases in precipitation were often accompanied with decreases in radiation and vice versa (a)

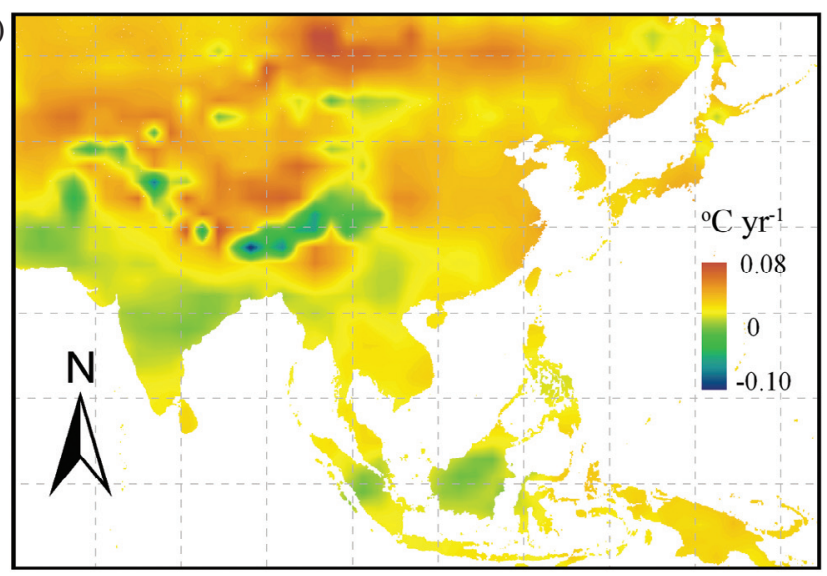

(c)

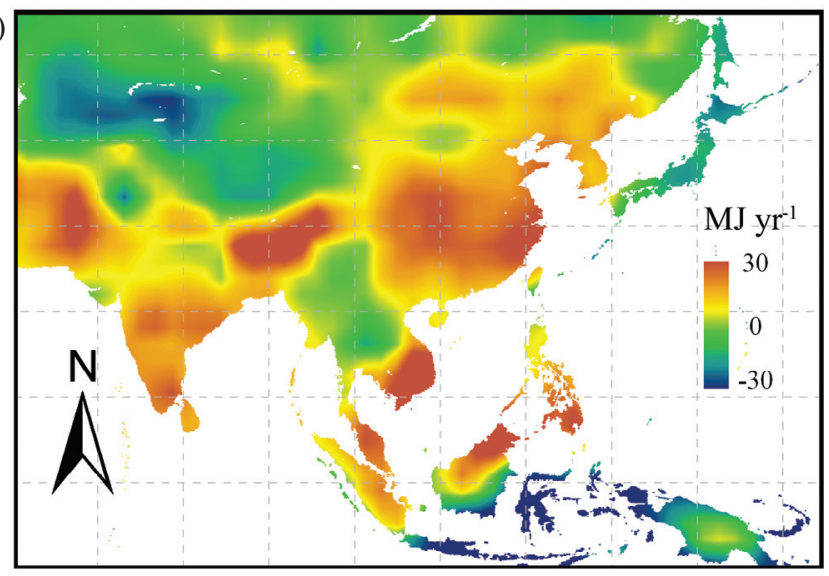

(b)
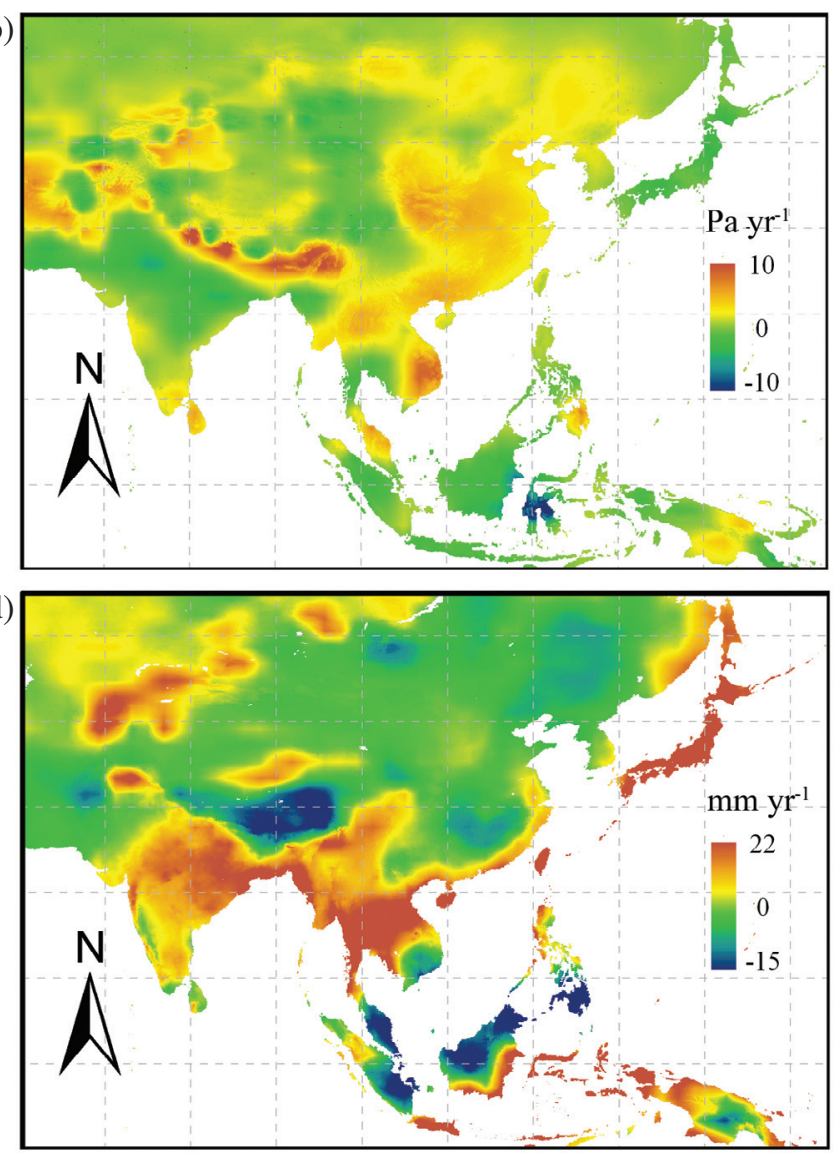

Fig. 5. Changes of (a) annual mean temperature, (b) annual mean vapor pressure deficit (VPD), (c) annual total solar radiation, and (d) annual total precipitation. Negative values represent decreasing change rates while positive values represent increasing change rates. 
(Figs. 5c - d). Therefore, the enhancement effects on NPP from increasing radiation were suppressed by decreasing precipitation in areas in which water availability is the predominantly limiting factor of NPP. Increases in precipitation were also accompanied with decreases in VPD (Figs. 5b and d). In addition, decreases in VPD mainly occurred in areas with a higher temperature (Figs. 5a - b). Lower VPD can enhance stomatal conductance and consequently NPP at a certain degree and vice versa. Increases in temperature can prolong growing seasons at high latitudes and caused NPP to increase. However, increasing temperature can also cause $R_{h}$ to increase and NPP to decrease, especially under dry conditions and at lower latitudes. Thus, the increase in precipitation and decrease in VPD caused NPP to increase significantly in the western part of this study area and India (Figs. 3c, 5b, and 5d). The decrease in precipitation and increases in temperature and VPD overwhelmed the positive effect of increasing radiation on NPP and caused NPP to decrease in Mongolia and Northeast Plain of China (Figs. 3 and 5). Increases in temperature and decreases in precipitation occurred in central China. Such configuration of temperature and precipitation changes resulted in decreases in NPP in these areas.

Some studies have shown that a strong link between warming and vegetation growth in the northern region (Zhou et al. 2001), but warming might be expected to have negative impacts on vegetation growth in warm regions by increasing evapotranspiration (Liang et al. 2003). During the period from 1982 to 2006, the annual NPP was positively correlated with annual precipitation in $80 \%$ areas of East Asia. In the western part of this study area, Mongolia, Northeast China and India Peninsula, the positive correla- tion between NPP and precipitation was at the 0.01 significance level, implying the key role of water in limiting terrestrial NPP in these areas. NPP showed an increasing trend in pan Southeast Asia although precipitation decreased. Precipitation was sufficient for vegetation growth and not a key limiting factor of NPP here. Instead, decreasing VPD and temperature and increasing radiation might drive the increase of NPP in these regions. In Tibetan Plateau, western part of the study area, and southern piedmont of Himalayas, increases in temperature also caused NPP to increase.

\subsection{Response of NPP to ENSO}

Annual NPP declined in four intense and persistent El Niño events before 2000 (1982 - 1983, 1987, 1991 to 1994, 1997 - 1998) and two weak periods after 2000 (2002 - 2003, 2004 - 2005) (Fig. 6). The negative correlation between annual NPP and annual MEI (the multivariate ENSO index indicating the intensity of ENSO) was at the 0.05 significance level in Thailand, Burma, Vietnam and pan Southeast Asia. ENSO events resulted in decreases in NPP in Af and tropical savanna and monsoon climate (Am_Aw) zones (Figs. 4b - c) possibly due to the significant increase in temperature (Hashimoto et al. 2004). Seasonal NPP varied with seasonal fluctuations of El Niño events and lagged El Niño events by about 3 - 6 months or more. Our results also suggested that El Niño events happening in spring, summer and fall could cause decrease in NPP. Otherwise, these events in winter could cause NPP to increase.

During the strong El Niño periods, NPP in East Asia decreased and atmospheric $\mathrm{CO}_{2}$ concentration increased largely, implying the crucial role of terrestrial ecosystems

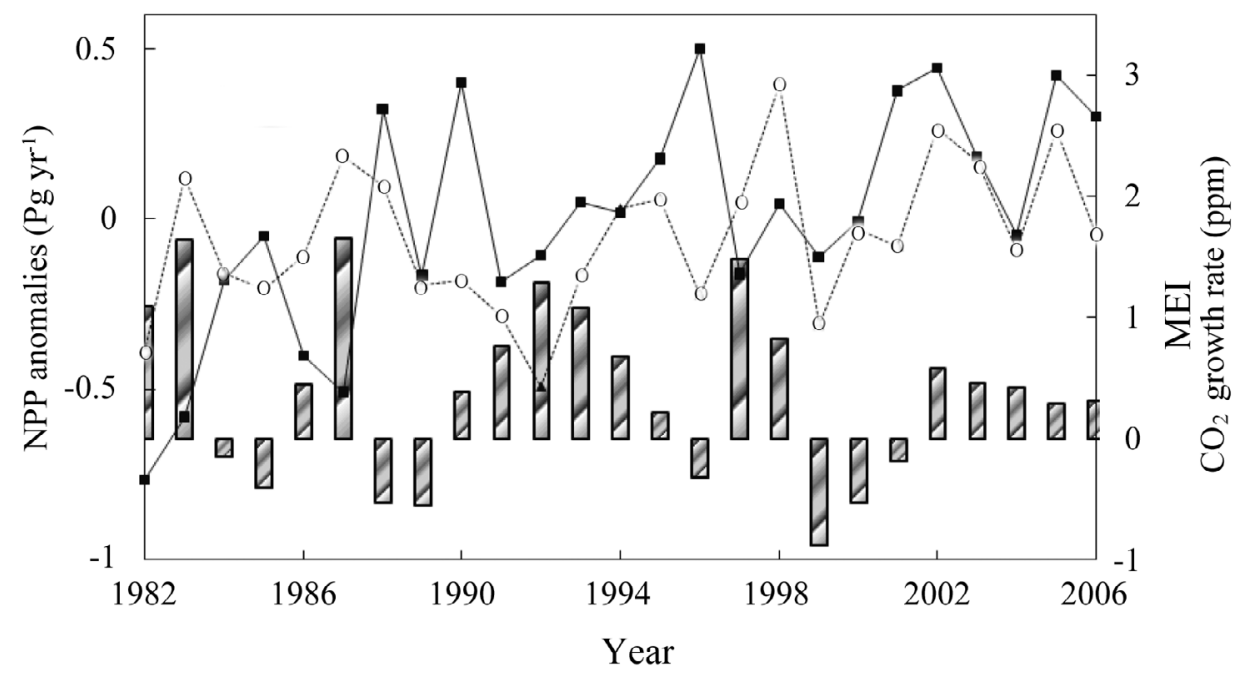

$\longrightarrow$ Annual MEI $\rightarrow \triangle \mathrm{NPP} \quad \cdots-\cdots-\cdots \cdot \mathrm{CO}_{2}$ growth rate

Fig. 6. Temporal trends of departures of annual NPP from the average, annual increase rate of $\mathrm{CO}_{2}$ concentration measured at MLO and the multivariate ENSO index (MEI) in East Asia from 1982 to 2006. The positive values of MEI denote El Niño and negative values represent La Niña. 
in East Asia in the global carbon cycle. However, NPP increased slightly from 1991 to 1992 (also El Niño year) but the $\mathrm{CO}_{2}$ growth rate declined drastically. This phenomenon was perhaps due to the enhancement effect of Mount Pinatubo eruption in 1991 over negative effect of the weak El Niño perturbation on terrestrial carbon sequestration and the lag in physiological responses of vegetations. The eruption of Mount Pinatubo in 1991 promoted photosynthesis due to increased diffused radiation ( $\mathrm{Gu}$ et al. 2003; Reichenau and Esser 2003) and reduced heterotrophic respiration due to decreases in temperature. However, the cooling effect shortened the growing-season length, leading NPP to decrease at mid- and high latitudes. The integrated effects of El Niño and Mount Pinatubo eruption caused the smallest annual increase rate of atmospheric $\mathrm{CO}_{2}$ in 1992 during the period from 1982 to 2006. However, the interactions of El Niño, atmospheric $\mathrm{CO}_{2}$ increase rate and NPP still needs comprehensive investigation in the near future.

\subsection{Uncertainties}

The simplification of complex natural ecological processes and the assumption of the credibility of upscaling parameterization might be sources of biases in simulated NPP. Apart from the limitations in the model itself, inaccuracies in input data and the differences in the spatial resolution between simulated and observed NPP were the major contributors to the disagreement between simulated and observed GPP/NPP. The impacts of the possible errors in input data and two key parameters in BEPS on simulated NPP were assessed through sensitivity analysis simulations (Table 3), which were quantified using the response coefficient (Williams et al. 2012):

$S=\frac{\Delta N P P}{N P P} \frac{P}{\Delta P}$

where $S$ is response coefficient, and equivalent to the relative change in an independent variable (e.g., NPP in this study) caused a relative change in the dependent variable $(P)$. In each sensitivity experiment, one input variable was imposed a $25 \%$ relative change (negative or positive) and applied to the study region from 1982 to 2006 in order to obtain a detectable response in NPP but we discussed the sensitivities by a $\pm 1 \%$ relative change.

Simulations show that the changes of $\pm 1 \%$ in the meteorological input into the BEPS model will cause changes of $-0.02 \%$ to $0.42 \%$ in the magnitude of simulated NPP (Table 3). It indicates that simulated NPP is more sensitive to errors in precipitation data than to errors of other meteorological inputs (Table 3). As indicated by Zhao et al. (2006), the NCEP reanalysis data overestimates solar radiation and underestimates temperature and VPD. Only the systematic error in radiation was corrected using the method developed by Feng et al. (2007). However, the remaining errors in temperature and VPD might lead errors to simulated NPP. It is shown that a $1 \%$ error in temperature and VPD translates into a $0.05 \%-0.37 \%$ error in estimated NPP.

The time series of LAI was constructed from the 15day composite GIMMS NDVI using the NDVI-LAI lookup table developed by Myneni et al. (2002). The saturation of NDVI under the condition of dense vegetation also might have led to the underestimation of high LAI and consequently simulated NPP. The sensitivity analysis indicated that errors of $1 \%$ in LAI would result in a bias of about $0.55 \%$ in the amplitude of the simulated NPP (Table 3). Although various calibrations and corrections were implemented on satellite data to generate GIMMS NDVI, which was validated in various landscapes (Gebremichael and Barros 2006), the orbital degradation of AVHRR is still possible to cause an underestimation of NDVI and hence NPP in recent years (Cao et al. 2004).

Land cover has considerable effect on NPP. Although the quality of the land cover data used in this study has been proved high, there are still errors in some areas. In addition, land cover changes have occurred dramatically in some parts of the study area, such as the eastern coastal areas of China. The application of a static land cover map might result in uncertainties in simulated NPP in areas with land cover changes in the study period.

Simulated NPP was sensitive to two key parameters $\left(\mathrm{g}_{\max }\right.$ and $\mathrm{V}_{\mathrm{cmax}}$ ) (Table 3) due to their direct effects on the calculation of GPP. Currently, these parameters were determined through model calibration using field measurements of GPP and NPP. Terrestrial ecosystems in East Asia are diverse. They should be optimized using measured data in more ecosystems especially in the tropical climate zone.

Table 3. Sensitivity of simulated NPP to different sources of errors across the study region from 1982 to 2006 .

\begin{tabular}{|c|c|c|c|c|}
\hline Sources & $\begin{array}{l}\text { Perturbed } \\
\text { estimate }\end{array}$ & $\begin{array}{c}\text { Impact } \\
\text { on NPP } \\
(\%)\end{array}$ & $\begin{array}{l}\text { Perturbed } \\
\text { estimate }\end{array}$ & $\begin{array}{c}\text { Impact } \\
\text { on NPP } \\
(\%)\end{array}$ \\
\hline Precipitation & & 0.42 & & -0.12 \\
\hline Minimum temperature & & -0.02 & & 0.17 \\
\hline Maximum temperature & & 0.03 & & 0.26 \\
\hline Radiation & & 0.30 & & -0.05 \\
\hline Vapor pressure deficit & 170 & -0.37 & & 0.14 \\
\hline Leaf area index & & 0.55 & & -0.44 \\
\hline $\mathrm{g}_{\max }$ & & 0.60 & & -0.14 \\
\hline $\mathrm{V}_{\mathrm{cmax}}$ & & 0.70 & & -0.38 \\
\hline
\end{tabular}




\section{CONCLUSIONS}

In this study, we explore the variability of terrestrial NPP and its linkage with climate and vegetation in East Asia over 25 years from 1982 to 2006 at $8-\mathrm{km}$ resolution through integrating a process-based ecological model with satellite-derived data, soil data and climatic data. Simulation experiments were conducted to identify the roles of climate and vegetation changes in driving NPP changes. Our key conclusions are as follows:

(1) The annual total NPP in the entire study area was 11.27 $\mathrm{Pg} \mathrm{C} \mathrm{yr}^{-1}$ averaged over the 25 -year period. Annual total NPP significantly increased from $10.83{\mathrm{Pg} \mathrm{C} \mathrm{yr}^{-1}}^{-1}$ in the early 1980s to $11.58 \mathrm{Pg} \mathrm{C} \mathrm{yr}^{-1}$ in the 2000s. Simulated annual NPP exhibited a southeast-northwest gradient and decreased from tropical broadleaf forests in Southeast Asia to desert areas in the continental interior.

(2) Vegetation change was the dominant factor affecting NPP from 1982 to 2006 in the eastern part of the study region, while climate change regulated the trends of NPP in interior and northern parts of the study region. NPP trends were determined mainly by the changes of precipitation in northern and southwestern regions. Decreased temperature tended to induce the decrease of NPP in Tibetan Plateau. Precipitation and VPD were responsible for NPP trends in North and Northeast Plain of China while radiation played a key role in regulating the temporal trends of NPP in South China.

(3) Our simulations show that precipitation and VPD were more important factors determining NPP than temperature and radiation in East Asia implying that NPP in East Asia will possibly decrease with the decrease of water availability caused by global warming in the future.

With a two-leaf photosynthetic stratification approach, the BEPS model largely overcomes the deficiencies of the big-leaf model since it properly describes the highly non-linear response of leaf photosynthesis (sunlit and shaded leave groups) to environment conditions. Although NPP estimated by the BEPS model was well validated with measured NPP from inventory data, some internal quasi-empiricism in BEPS and external uncertainties from input sources would possibly reduce modeling accuracy. For example, the dailystep BEPS model integrates the instantaneous Farquhar's model to calculate daily GPP based on the daily means of irradiance and temperature and is unable to capture the diurnal variability of NPP. Stomatal conductance is calculated by empirically descaling $\mathrm{g}_{\max }$ with scalars of environmental factors such as photosynthetic photon flux density, temperature and VPD. This leads calculated stomatal conductance and NPP sensitive to parameters in the models calculating stomatal conductance. Ecosystems are very diverse in East Asia, Thus, more measurements are required to better the parameterization of the model. Furthermore, tropical zone plays an important role in global carbon cycle. Reanalysis meteorological data and remote sensing data have large uncertainties. More effort should be taken to improve the quality of input meteorological and LAI data. The effects of land cover changes due to deforestation and urbanization on NPP were not addressed in this study. These limitations are worthy of thorough study in the future.

Acknowledgements This study was supported by the State Key Basic Research Development Program of China (2010CB833503), National Science Foundation of China (40871240/D011004, 30721140307), the Priority Academic Program Development of Jiangsu Higher Education Institutions (PARO) and Jiangsu Graduate Innovation Program (CX09B_223Z). We thank Prof. Jing Ming Chen at University of Toronto to provide suggestions and revisions. We also thank Prof. Jun Asanuma at University of Tsukuba, and Yingnian Li at Chinese Academy Sciences to provide AsiaFlux data.

\section{REFERENCES}

Cao, M., S. D. Prince, J. Small, and S. J. Goetz, 2004: Remotely sensed interannual variations and trends in terrestrial net primary productivity 1981-2000. Ecosystem, 7, 233-242, doi: 10.1007/s10021-003-0189-x. [Link]

Chen, J. M., J. Liu, J. Cihlar, and M. L. Goulden, 1999: Daily canopy photosynthesis model through temporal and spatial scaling for remote sensing applications. Ecol. Model., 124, 99-119, doi: 10.1016/S0304-3800(99)00 156-8. [Link]

Chen, J. M., F. Deng, and M. Chen, 2006: Locally adjusted cubic-spline capping for reconstructing seasonal trajectories of a satellite-derived surface parameter. IEEE Trans. Geosci. Remote Sensing, 44, 2230-2238, doi: 10.1109/TGRS.2006.872089. [Link]

Chen, J. M., G. Mo, J. Pisek, J. Liu, F. Deng, M. Ishizawa, and D. Chan, 2012: Effects of foliage clumping on the estimation of global terrestrial gross primary productivity. Global Biogeochem. Cycles, 26, GB1019, doi: 10.1029/2010GB003996. [Link]

Feng, X., G. Liu, J. M. Chen , M. Chen, J. Liu, W. M. Ju, R. Sun, and W. Zhou, 2007: Net primary productivity of China's terrestrial ecosystems from a process model driven by remote sensing. J. Environ. Manage., 85, 563-573, doi: 10.1016/j.jenvman.2006.09.021. [Link]

Foley, J. A., I. C. Prentice, N. Ramankutty, S. Levis, D. Pollard, S. Sitch, and A. Haxeltine, 1996: An integrated biosphere model of land surface processes, terrestrial carbon balance, and vegetation dynamics. Global Biogeochem. Cycles, 10, 603-628, doi: 10.1029/96GB02 692. [Link]

Gebremichael, M. and A. P. Barros, 2006: Evaluation of MODIS gross primary productivity (GPP) in tropical 
monsoon regions. Remote Sens. Environ., 100, 150166, doi: 10.1016/j.rse.2005.10.009. [Link]

Gu, L., D. D. Baldocchi, S. C. Wofsy, J. W. Munger, J. J. Michalsky, S. P. Urbanski, and T. A. Bolden, 2003: Response of a deciduous forest to the Mount Pinatubo eruption: Enhanced photosynthesis. Science, 299, 2035-2038, doi: 10.1126/science.1078366. [Link]

Hansen, M., R. DeFries, J. R. G. Townshend, and R. Sohlberg, 1998: UMD Global Land Cover Classification, 1 Kilometer, 1.0, Department of Geography, University of Maryland, College Park, Maryland, 1981-1994.

Hashimoto, H., R. R. Nemani, M. A. White, W. M. Jolly, S. C. Piper, C. D. Keeling, R. B. Myneni, and S. W. Running, 2004: El Niño-Southern Oscillation - Induced variability in terrestrial carbon cycling.J.Geophys. Res., 109, D23110, doi: 10.1029/2004JD004959. [Link]

Hazarika, M. K., Y. Yasuoka, A. Ito, and D. Dye, 2005: Estimation of net primary productivity by integrating remote sensing data with an ecosystem model. Remote Sens. Environ., 94, 298-310, doi: 10.1016/j.rse.2004. 10.004. [Link]

Hijmans, R. J., S. E. Cameron, J. L. Parra, P. G. Jones, and A. Jarvis, 2005: Very high resolution interpolated climate surfaces for global land areas. Int. J. Climatol., 25, 1965-1978, doi: 10.1002/joc.1276. [Link]

Houghton, J. T., Y. Ding, D. J. Griggs, M. Noguer, P. J. van der Linden, X. Dai, K. Maskell, and C. A. Johnson, 2001: Climate Change 2001: The Scientific Basis. Contribution of Working Group 1 to the Third Assessment Report of the Intergovernmental Panel on Climate Change, IPCC.

Ito, A., 2008: The regional carbon budget of East Asia simulated with a terrestrial ecosystem model and validated using AsiaFlux data. Agric. For. Meteorol., 148, 738747, doi: 10.1016/j.agrformet.2007.12.007. [Link]

Ju, W., P. Gao, J. Wang, Y. Zhou, and X. Zhang, 2010: Combining an ecological model with remote sensing and GIS techniques to monitor soil water content of croplands with a monsoon climate. Agric. Water Manage., 97, 1221-1231, doi: 10.1016/j.agwat.2009.12.007. [Link]

Keeling, R. F., S. C. Piper, A. F. Bollenbacher, and J. S. Walker, 2009: Atmospheric $\mathrm{CO}_{2}$ records from sites in the SIO air sampling network. In: Trends: A Compendium of Data on Global Change. Carbon Dioxide Information Analysis Center, Oak Ridge National Laboratory, US Department of Energy, Oak Ridge, Tenn., USA.

Kite, G. W., 1988: Frequency and Risk Analyses in Hydrology. Water Resources Publications, Littleton, Colorado.

Li, W., G. M. Zhang, and Z. J. Li, 2008: The spatio-temporal pattern of net primary productivity of terrestrial ecosystem in East Asia region. Acta Ecologia Sinica,
28, 4173-4183. (in Chinese)

Liang, X., Z. Xie, and M. Huang, 2003: A new parameterization for surface and groundwater interactions and its impact on water budgets with the variable infiltration capacity (VIC) land surface model. J. Geophys. Res., 108, 8613, doi: 10.1029/2002JD003090. [Link]

Liu, J., J. M. Chen, J. Cihlar, and W. M. Park, 1997: A process-based boreal ecosystem productivity simulator using remote sensing inputs. Remote Sens. Environ., 62, 158-175, doi: 10.1016/S0034-4257(97)00089-8. [Link]

Liu, J, J. M. Chen, J. Cihlar, and W. Chen, 2002: Net primary productivity mapped for Canada at $1-\mathrm{km}$ resolution. Glob. Ecol. Biogeogr., 11, 115-129, doi: 10.10 46/j.1466-822X.2002.00278.x. [Link]

Liu, R., J. M. Chen, J. Liu, F. Deng, and R. Sun, 2007: Application of a new leaf area index algorithm to China's landmass using MODIS data for carbon cycle research. J.Environ. Manage., 85, 649-658, doi: 10.1016/j.jenvman.2006.04.023. [Link]

Luo, T. X., 1996: Patterns of biological production and its mathematical models for main forest types of China, Beijing, Graduate School, Chinese Academy of Sciences. (in Chinese)

Matsushita, B. and M. Tamura, 2002: Integrating remotely sensed data with an ecosystem model to estimate net primary productivity in East Asia. Remote Sens. Environ., 81, 58-66, doi: 10.1016/S0034-4257(01)00331-5. [Link]

Myneni, R. B., S. Hoffman, Y. Knyazikhin, J. L. Privette, J. Glassy, Y. Tian, Y. Wang, X. Song, Y. Zhang, G. R. Smith, A. Lotsch, M. Friedl, J. T. Morisette, P. Votava, R. R. Nemani, and S. W. Running, 2002: Global products of vegetation leaf area and fraction absorbed PAR from year one of MODIS data. Remote Sens. Environ., 83, 214-231, doi: 10.1016/S0034-4257(02)00074-3. [Link]

Nemani, R. R., C. D. Keeling, H. Hashimoto, W. M. Jolly, S. C. Piper, C. J. Tucker, R. B. Myneni, and S. W. Running, 2003: Climate-driven increases in global terrestrial net primary production from 1982 to 1999. Science, 300, 1560-1563, doi: 10.1126/science.1082750. [Link]

Piao, S., J. Fang, L. Zhou, B.Zhu, K. Tan, and S. Tao, 2005: Changes in vegetation net primary productivity from 1982 to 1999 in China. Global Biogeochem. Cycles, 19, GB2027, doi: 10.1029/2004GB002274. [Link]

Piao, S., P. Ciais, P. Friedlingstein, N. de Noblet-Ducoudré, P. Cadule, N. Viovy, and T. Wang, 2009: Spatiotemporal patterns of terrestrial carbon cycle during the $20^{\text {th }}$ century. Global Biogeochem. Cycles, 23, GB4026, doi: 10.1029/2008GB003339. [Link]

Pisek, J. and J. M. Chen, 2007: Comparison and validation of MODIS and VEGETATION global LAI products 
over four BigFoot sites in North America. Remote Sens. Environ., 109, 81-94, doi: 10.1016/j.rse.2006.12.004. [Link]

Reichenau, T. G. and G. Esser, 2003: Is interannual fluctuation of atmospheric $\mathrm{CO}_{2}$ dominated by combined effects of ENSO and volcanic aerosols? Global Biogeochem. Cycles, 17, 1094, doi: 10.1029/2002GB002025. [Link]

Ropelewski, C. F. and M. S. Halpert, 1987: Global and regional scale precipitation patterns associated with the El Niño/Southern Oscillation. Mon. Weather Rev., 115, 1606-1626, doi: 10.1175/1520-0493(1987)115<1606: GARSPP $>2.0 . \mathrm{CO} ; 2$. [Link]

Running, S. W. and J. C. Coughlan, 1988: A general model of forest ecosystem processes for regional applications I. Hydrologic balance, canopy gas exchange and primary production processes. Ecol. Model., 42, 125-154, doi: 10.1016/0304-3800(88)90112-3. [Link]

Sprintsin, M., J. M. Chen, A. Desai, and C. M. Gough, 2012: Evaluation of leaf-to-canopy upscaling methodologies against carbon flux data in North America. J. Geophys. Res., 117, G01023, doi: 10.1029/2010JG001407. [Link]

Williams, C. A., G. J. Collatz, J. Masek, and S. N. Goward, 2012: Carbon consequences of forest disturbance and recovery across the conterminous United States. Global Biogeochem. Cycles, 26, GB1005, doi: 10.1029/20 10GB003947. [Link]
Wolter, K. and M. Timlin, 1998: Measuring the strength of ENSO events: How does 1997/98 rank? Weather, 53, 315-324.

Yu, D., P. Shi, H. Shao, W. Zhu, and Y. Pan, 2009: Modelling net primary productivity of terrestrial ecosystems in East Asia based on an improved CASA ecosystem model. Int. J. Remote Sens., 30, 4851-4866, doi: 10.1080/01431160802680552. [Link]

Zhang, F. M., W. Ju, J. M. Chen, S. Wang, X. Zhao, S. Han, and J. Asanuma, 2010: Preliminary study on evapotranspiration in East Asia using the BEPS ecological model. J. Natl. Resour., 25, 1596-1606. (in Chinese)

Zhao, M., S. W. Running, and R. R. Nemani, 2006: Sensitivity of moderate resolution imaging spectroradiometer (MODIS) terrestrial primary production to the accuracy of meteorological reanalyses. J. Geophys. Res., 111, G01002, doi: 10.1029/2004JG000004. [Link]

Zheng, D., S. Prince, and R. Wright, 2003: Terrestrial net primary production estimates for $0.5^{\circ}$ grid cells from field observations - A contribution to global biogeochemical modeling. Global Change Biol., 9, 46-64, doi: 10.1046/j.1365-2486.2003.00534.x. [Link]

Zhou, L., C. J. Tucker, R. K. Kaufmann, D. Slayback, N. V. Shabanov, and R. B. Myneni, 2001: Variations in northern vegetation activity inferred from satellite data of vegetation index during 1981 to 1999. J. Geophys. Res., 106, 20069-20083, doi: 10.1029/2000JD000115. [Link] 